\title{
4
}

\section{Lost in Transition? On the Migration to English Language Research Publications}

\author{
Mads P. Sørensen, Mitchell Young, \\ and Pernille Bak Pedersen
}

\section{Introduction}

This chapter focuses on the difficult balance that universities and university researchers in the Nordic countries, and beyond, are expected to achieve today with regard to the publication of research results. On the one hand, universities are expected to perform and compete globally, while on the other hand, they still have responsibilities nationally and locally. Nordic universities are primarily public entities financed by tax payments, but a bigger and bigger part of their activities is directed towards the global knowledge market. Nordic universities compete with universities in the rest of the world for high performing, international students and for the best scientists; they work with international partners in transnational networks and produce highly specialized research for the global science community and they employ an increasing number of

M. P. Sørensen $(\bowtie) \bullet$ P. B. Pedersen

Aarhus University, Aarhus, Denmark

e-mail: mps@ps.au.dk; pernillebp@au.dk

M. Young

Charles University, Prague, Czech Republic

(C) The Author(s) 2019 
academic staff from non-Nordic countries (Gregersen 2014). As part of this development, Nordic universities also produce a significant and growing number of research publications in English. In the present chapter, we examine this development and discuss which implications it has for universities that want to be responsible both towards local taxpayers and the global science system.

Today, around $86 \%$ of all research publications from Danish universities are published in English, and as we will show in this chapter, especially the Humanities and the Social Sciences have seen a dramatic change in research publication language over the last 20 years, from Danish to English. This development is not unique for Denmark but part of a global trend. With the transnationalization of research production and research institutions (Sørensen and Schneider 2017), an increasing focus on metrics and pressure to attain excellence (Sørensen et al. 2016), and the subsequent growing orientation towards the global science system, or what Wagner (2008) calls "the new invisible college", the research language par excellence has become English. This has been the case in the natural sciences and health sciences for many years, but within the last couple of decades, the Humanities and the Social Sciences have seen a similar shift in publication language away from national languages towards English. This development requires our attention and understanding-and we need to reflect on what a responsible language strategy is for present-day universities outside the Anglo-Saxon world.

That one language dominates within academia is historically not a new situation. When the first universities were founded in the twelfth century, the dominating language was Latin. Due to the universities'strong connection to the church, this continued to be the case for many centuries. Latin was thus the dominant language at universities up until the beginning of the nineteenth century when nationally oriented universities were founded-inspired by the Humboldt University in Berlin (founded in 1809/1810). With the modern university's strong connection to the nation state and its role as an institution for the educating of civil servants, for example, national languages gradually took over Latin's commanding role (Bull 2004, 37).

Denmark is an example of this development. When Copenhagen University was founded in 1479 , the official language of the university 
was Latin, and it stayed that way until the eighteenth century, when Danish gradually began to take over as the preferred teaching language (Mortensen and Haberland 2012). As a language of publication, Danish also became increasingly popular during the eighteenth century. Right from its establishment in 1742, the Royal Danish Academy of Science and Letters, for example, published its treatises in Danish. According to Mortensen and Haberland $(2012,181)$, Danish was, at that time, associated with progress, whereas Latin was the language of tradition. In the nineteenth century, following Humboldt's idea of emphasizing a stronger connection between the state and the university, Danish gradually took over both as the dominant language for teaching and for publication. The last fortress for Latin at Copenhagen University was the doctoral thesis. Up until the middle of the century, most theses were still written in Latin and the public defence of the theses had to be done in Latin (Mortensen and Haberland 2012, 182). The last year a doctoral thesis written in Latin was accepted for public defence at Copenhagen University was in the year 1900 .

Similarly, Danish has, today, come under pressure at Higher Education Institutions in Denmark. Wächter and Maiworm $(2014,43)$ found that $38 \%$ of all educational programmes at Danish Higher Education Institutions were taught in English in 2013/2014 — and, as mentioned above, around $86 \%$ of all research publications from Danish universities in 2017 were published in English. This development is not unique for Denmark but a global trend. Everywhere, English has become the dominant language for research communities, scientific journals and academic conferences (Kaplan 1993; Ammon 2001; Altbach 2013; Montgomery 2013). The topic has even become institutionalized as the academic field of "ERPP" (English for Research Publication Purposes) with its own conference PRISEAL (Publishing and Presenting Research InternationallyIssues for Speakers of English as an Additional Language) and the recently launched Journal of English for Research Publication Purposes. ${ }^{1}$ This leading role of English within academia has been understood in different ways (Kuteeva and McGrath 2014). It has been interpreted as a new "Lingua Franca" - a practical tool that makes it possible for researchers from different countries to understand each other-but also as a 
"Tyrannosaurus rex", that is, the idea that English intimidates and eats up all the other national languages within the academy (Swales 1997).

What this transformation away from national languages towards English means for researchers' text production has most profoundly been investigated by Lillis and Curry (2010). In a comprehensive ethnographic study, they examined the production of academic texts by 50 researchers from Slovakia, Hungary, Spain and Portugal. They followed the texts from draft to final versions, examined correspondence between the authors and the brokers (journals), and interviewed the authors. Among the main findings in their study were that publishing in English has pervaded evaluation and rewards systems for academics in all the countries studied (see also Gazzola 2012 for further discussion on the relationship between language and academic performance indicators). They describe the difficulties which that creates for academics for whom English is a second language, an aspect of their work that comes to similar conclusions as others who investigated this problem in other regions and disciplines (Flowerdew 1999; Hanauer and Englander 2011; Martín et al. 2014). Finally, they show that English is not a neutral medium but represents a distinct politics with a clear centre-periphery dynamic in which the centre is not merely the English language but the Anglophone academic world that dominates it. Consequently, any research that focuses on localities outside the Anglophone centre must be explicitly justified in order to become publishable.

In Denmark, Madsen in 2008 looked into the personal language strategies of researchers working within the Natural Sciences at Aarhus University (Madsen 2008). A key finding in her study was that it was the receiver group that was decisive for the researcher's choice of language. To her respondents, the increasing use of English primarily had to do with efficiency in communication. Without framing it in this way, Madsen's interviewees thus gave reasons for using English that resonate well with the idea of English as a lingua franca that enables them to communicate better with colleagues at conferences, and which makes it possible for peers outside Denmark to read and review their scientific publications and applications. However, it is also clear that there is more prestige given to English in the academy. Among other things, this has to do with the language of the best journals, which are all in English. The interviewees emphasized that one has to master English well, in order to do well in 
academia. Madsen analyses this development with inspiration from the French sociologist Pierre Bourdieu and points out that English is a "linguistic capital" in the academic field (Madsen 2008, 78).

A comparative study of the Nordic countries' language policies (Saarinen and Taalas 2017) shows that Denmark is unique among them in not having official language legislation or regulation at any level: national, sectorial (i.e. higher education) or institutional (i.e. as a requirement for institutional policy), though it is noted that most institutions have instituted one of their own volition. However, the issue is very much on the political agenda, as there have been several policy papers and reviews by the Danish Ministry of Culture in the first decade of the 2000s as well as significant media attention to the topic. On the surface both the state and the institutional policy papers support parallel lingualism (Danish and English)_but an analysis of the covert ideologies in the papers shows that this means more Danish and less English in the state policy papers and more English and less Danish in the policy papers of the institutions (Hultgren 2014a). In a separate article, Anna Kristina Hultgren (Hultgren 2014b) examines the relationship between rankings and what she terms 'Englishisation' using Denmark's eight universities as cases. While finding no statistically significant correlation between high rankings and levels of English presence among all the universities, she does find a relationship between low English presence and low rankings. These mixed results, she argues, mean that we cannot see English adaptation solely as a "passive capitulation to the global dominance of the English language" (Hultgren 2014b, 405), but also have to understand it as a strategic and context-dependent choice of the university.

In the following, we will first examine the development in English language research publications in Denmark in general. Thereafter, we focus on the development at Aarhus University, which is a comprehensive and prominent international university. Despite its young age (founded in 1928), it is one of the highest ranked universities in the Nordic countries and within the top 100 on various international ranking lists. ${ }^{2}$ The University has grown rapidly over the last two decades and has today around 40,000 students and 8000 members of staff.

As it will become clear in the following, all scientific fields in Denmark in general and at Aarhus University have experienced a radical change in 
publication language over the last two decades. Yet, it is the Social Sciences and the Humanities that have seen the biggest changes over these years. In order to better understand this development, we supplement the quantitative mapping of the changes in publication languages with interviews with researchers from the two departments within the Social Sciences and the Humanities at Aarhus University that have experienced the most dramatic changes since 2001. ${ }^{3}$ The interviews focus on the researchers' experiences of this development and their thoughts on the positive and negative implications of publishing more in English and less in Danish. We also talked to them about their understanding of university researchers' responsibilities towards the global science community and the local and national contexts in which they work.

The chapter ends with a discussion of the implications of the development towards publishing more research in English and less in Danish. Here, we also discuss the question of the responsibility of universities when it comes to publishing research.

\section{The Development in Publication Languages in Denmark from 2010 Onwards}

In 2017, 17 out of 20 research publications from Danish universities were published in English. ${ }^{4}$ As Fig. 4.1 shows, this number has increased steadily since 2010, where researchers from Danish universities published around 22,000 research publications in English and 6000 in Danish. There were also a small number of publications in third languages such as French and German, equivalent to $3 \%$ of the total research publications in 2010. Between 2010 and 2017, the number of English language research publications gradually increased to around 31,000, corresponding to $86 \%$ of the total number of research publications. In contrast, both the number and share of research publications in Danish decreased in the same period. In 2010, every fifth research publication from Danish universities was published in Danish. This number had decreased to around every eighth in 2017. The share of third language publications decreased to less than $2 \%$ in the same period. 


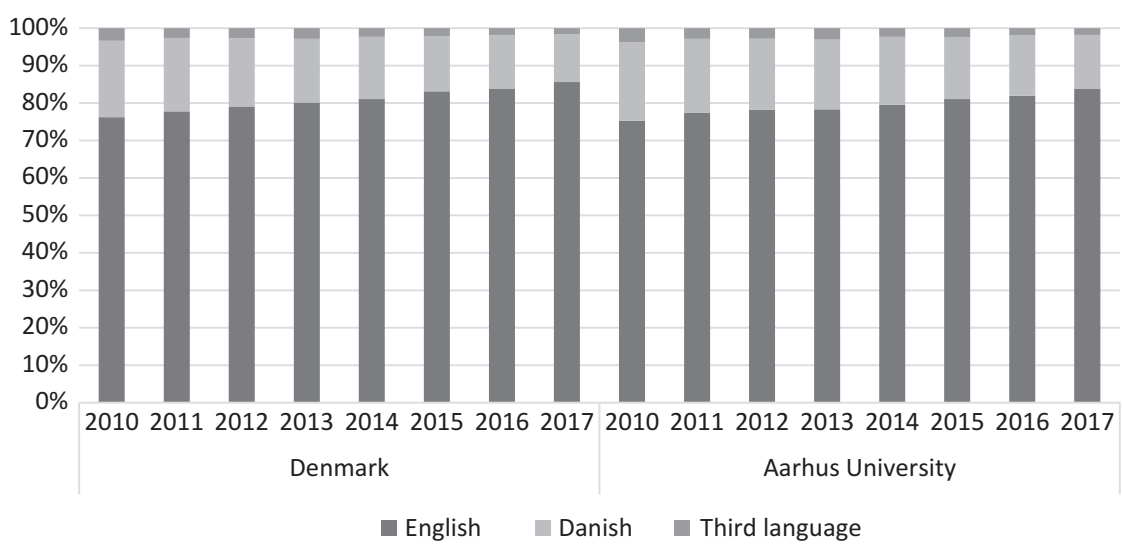

Fig. 4.1 Share of English, Danish and third language research publications, all Danish universities and Aarhus University. Source: The national database, "Forskningsdatabasen.dk"

As Fig. 4.1 also shows, a similar change in the publication patterns can be observed at Aarhus University. In 2010, English language research publications accounted for $75 \%$ of the more than 7000 research publications. Danish language publications accounted for 21\%, and third languages for $4 \%$. The total number of research publications rose to around 9000 in 2017, and the corresponding percentages for research languages were $84 \%$ English, 14.5\% Danish and 2\% third languages.

If we look at the development across main scientific areas at Danish universities, there are huge differences between the different areas in the share of English language research publications (cf. Fig. 4.2). ${ }^{5}$ However, all the main areas have experienced a growth in the number and share of English language publications over the period. Science and Technology already had around 90\% English language research publications in 2010, but this figure has now increased to more than $96 \%$. In the Humanities, where the majority of research publications were still published in Danish in 2010 , more than $55 \%$ of all research publications are now published in English. The Social Sciences have likewise experienced a significant increase, from around $59 \%$ to $70 \%$ over the period, as has Medical Science (from $84 \%$ to $92 \%$ ). 


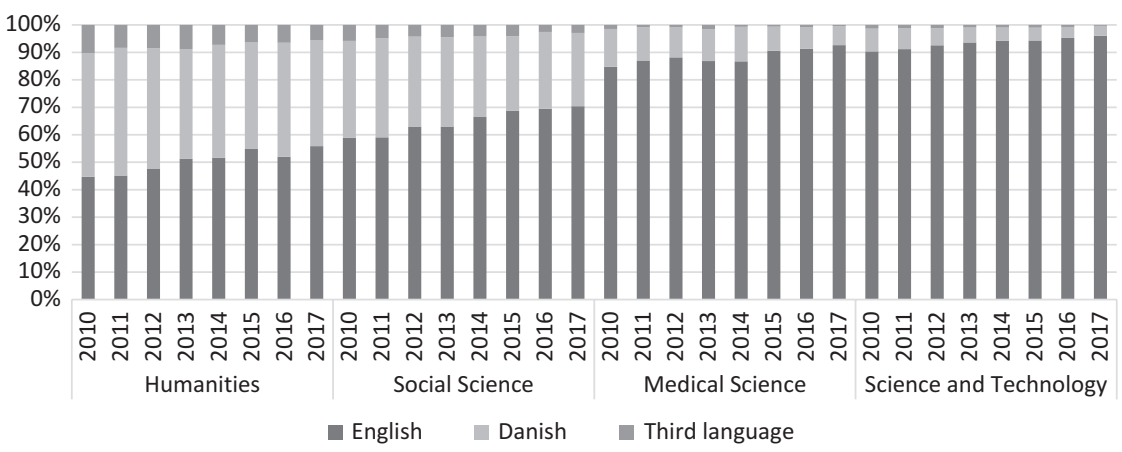

Fig. 4.2 The development in English, Danish and third language research publications across the four main scientific areas in Denmark. Source: The national database, "Forskningsdatabasen.dk"

\section{The Development in English Language Publications at Aarhus University}

In Fig. 4.3, the development from 2001 onwards within the different main areas at Aarhus University is displayed. ${ }^{6}$ The graph clearly shows that significant changes have taken place over the last 17 years within all scientific areas, but especially within the Humanities and the Social Sciences. While only $24 \%$ of the research publications from the Humanities were published in English in 2001, this figure had increased to $53 \%$ in 2017 , and, in the Social Sciences, a similar dramatic change from around $47 \%$ to about $80 \%$ has taken place.

We further looked into the different academic environments (schools and departments) within the Social Sciences and Humanities to find out, which among them had undergone the most significant transformations. Many of the departments had experienced radical changes in their publication patterns over this period. However, within the Social Sciences the Department of Management had undergone the most substantial changes. In 2001, 58\% of the research publications from the Department of Management were in English, whereas this in 2017 had changed to nearly $96 \% .^{7}$ This means that Danish as well as third languages have more or less disappeared as publication languages for research publications in this department. 


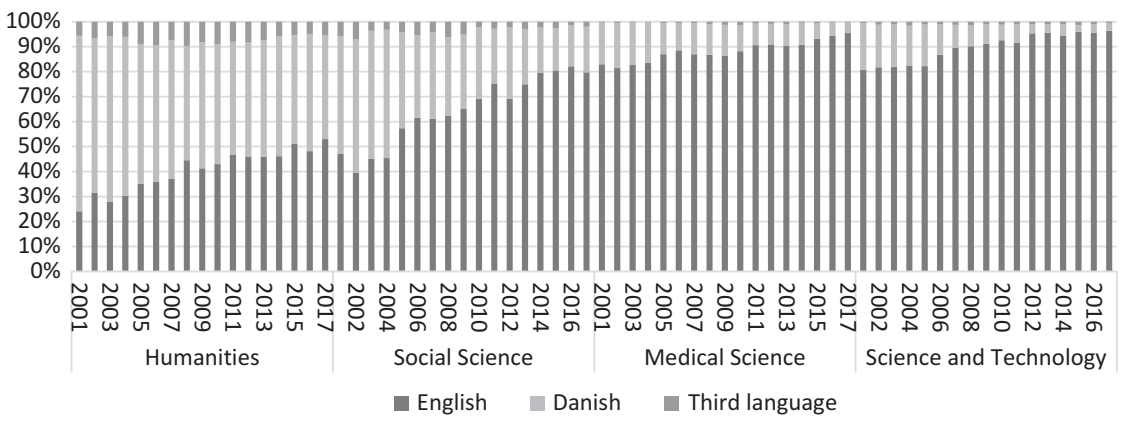

Fig. 4.3 Share of English, Danish and third language research publications across four main areas at Aarhus University. Source: The local "PURE" database at Aarhus University

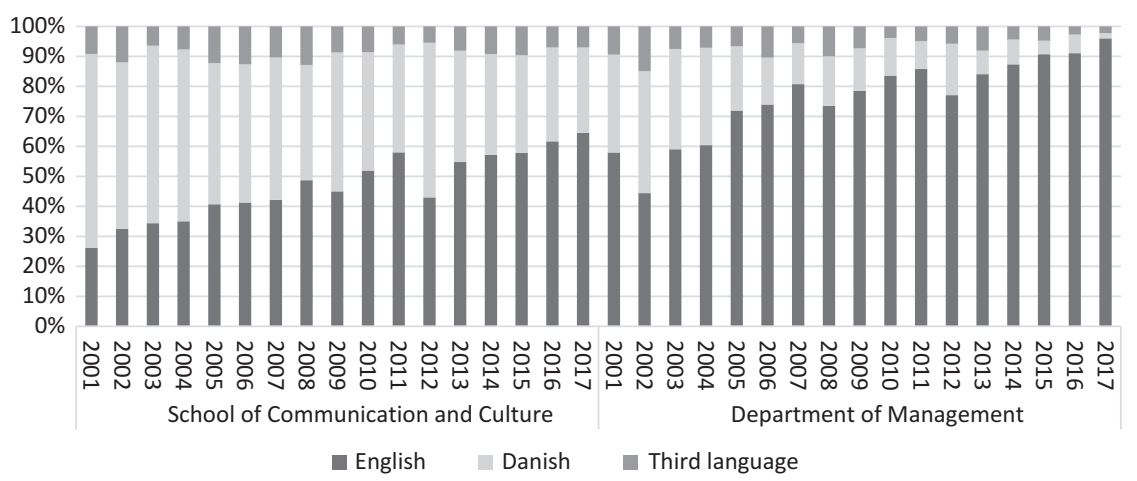

Fig. 4.4 The development in the share of English, Danish and third language research publications at the Department of Management and the School of Communication and Culture at Aarhus University. Source: The local "PURE" database at Aarhus University

Within the Humanities, it was the School of Communication and Culture that had undergone the biggest changes. ${ }^{8}$ Here, Danish was still the dominating publication language in 2001 with around $64 \%$ of the research publications published in Danish. This balance has now tipped, so that most publications now are in English. The share of English language research publications has gone up from about 26\% in 2001 to around $64 \%$ in 2017 . The development in the two scientific environments is shown in Fig. 4.4. 


\section{Push and Pull in the Migration to English}

In order to better understand these rather dramatic developments, we interviewed eight researchers from these two academic environments about their experiences and understandings of the changes. The eight researchers (three women and five men) are all professors or associate professors at the Department of Management or the School of Communication and Culture. They have also all of them been employed at Aarhus University for most of the monitored period and therefore themselves experienced the changes. In the Department of Management we talked to researchers from the sections Corporate Communication and Organization, Strategy and Accounting. In the School of Communication and Culture, we interviewed researchers from the Department of Art History, Aesthetics and Culture and Museology as well as the Department of Scandinavian Studies and Experience Economy. These sections and departments were likewise chosen based on an analysis of the changes that had taken place, so that we interviewed researchers from the scientific environments, which had seen the most radical changes.

In the following, we report on the findings from the interviews. Our analysis strategy is inspired by migration studies. We examine the shifts in publication language patterns as a form of migration from Danish and other languages to English. One of the most established theories explaining migration is the "push-pull" model (see, for example, Portes and Böröcz 1989; Petersen 1958), which categorizes hardships in the region of origin as push factors and opportunities in the destination region as pull factors. The combination and strengths of the various push and pull factors condition the effects of migration flows. In Table 4.1 the findings from our interviews are categorized according to push and pull factors, followed by an in-depth discussion.

\section{Push Factors}

\section{Danish}

The concept of push factors, when translated for publication practices, identifies pressures that create an environment that is not conducive to 
Table 4.1 Push and pull factors in the migration from Danish to English language research publications

\begin{tabular}{lll}
\hline & Danish & English \\
\hline Push & National publication system & Subject of study \\
& Funding & Methods and theories \\
& University policy & Thinking and writing \\
& Department management & \\
& Career advancement & \\
Pull & Identity & Legitimacy and prestige \\
& Students & Socialization \\
& Public sphere & Career advancement \\
& Journals & Cooperation and belonging \\
& Public accessibility & Audience \\
& & Quality \\
\hline
\end{tabular}

Danish language publication. Push factors are negatively connoted and reflect a pushing away from something. These push factors also encourage (we might even say that they push towards) English publication, and as we have seen in the previous section the push away from Danish has not led to an increase in publication in other languages than English, nevertheless, the perception of researchers is different for this set of factors than for what we characterize as pull factors. While there are corresponding pull factors of English, they are not just a mirror image of these push factors, but can be better characterized through legitimacy, socialization and career advancement, as we will explain in the section below.

Five main types of push factors come out of our interviews. To some extent they are interconnected, as bibliometrics and the national points system for publications percolates from the top down and has an impact on the university-level pressures as well as the department and individuallevel ones. The conditions are set at the highest political levels: "there is a political wish from the government, from parliament, that all research should be international... the legislators tend to think that international is English (6)". This second part of the statement was both a reflection of reality, which is to say that for many of the researchers we spoke with, this was uncontested, but on the other hand, a criticism of the conflation of these two terms. The interpenetration of the national can be seen clearly in this comment: "I think it basically has to do with the signals that have been sent politically. Any young scholar with a minimum of sensitivity 
could see from the early years of this century that a career in the system would require an orientation towards the English language and publications in international journals (4)".

The national publication points system is perceived as one of the push factors away from Danish:

after the bibliometric system was implemented, suddenly it was very difficult getting the best scores for publishing in the Danish journals, so you kind of had to publish in an international journal to get two points [the highest level], so... and I don't necessarily think that people care that much about the points, but there is still this, somehow, pressure. (7)

The claim that points were not intrinsically valued by researchers was reflected in many of the responses. Despite not wanting to clearly pin down points as the sole cause of this publication shift, there was a clear sense of bibliometrics being central in developing pressure towards publishing in English:

The thing about pressure is really difficult, because no one is telling me 'you have to publish in English', and no one is telling me 'you have to publish in Danish', but... but I think the whole structure around publications is becoming more and more inclined to publishing in English, for instance through the bibliometric system. (7)

Funding also puts pressure on researchers to move away from Danish. "In the early century, just around the university law and the rising pressure towards English language it was almost impossible to get funding from the research foundation to publish anything that was not in English (4)". In this regard however, there was a sense that this pressure was easing up a bit, and that in more recent years it had again become at least possible.

The university policies also favour publications in English, but researchers do not comment strongly on this level as affecting their decisions. They see the university seeking to brand itself internationally and pursuing higher rankings on international lists. What comes through more strongly is the sense that the university is obligated to make this empha- 
sis, but the stronger pressures come from the departmental or School management. In the humanities, the dean's level even appears to play a bit of a buffering role:

the dean of the humanities, not my department, has said explicitly: "Don't bother about the bibliometrics. Don't bother. Publish your things where it makes sense"-in an academic sense of the word. Which is a relief. He did that 2 or 3 years ago. That has in my experience taken a bit of the drama out of this. Up till then, even I had started calculating about what I should do in order to legitimize [my research]. I have published quite a few English language articles because of that consideration. I don't do that anymore. I mean... It is not that I distanced myself from the articles, they were fine, but the reason I did them in English was this pressure existed. (4)

The pressure from department management varied between the two departments we studied. In the social sciences, there was a more formal approach: a list of around 50 journals conscribed the acceptable publication outlets. This list derived not from the national system but from the Financial Times; that said, it does not diverge from the national bibliometric system, as it is a subset of the high impact factor (level 2) publications. All of the publications are in English. The implementation of this system came from a management change in the department:

I think actually the shift from going from Danish to English, it kind of reflected that new management. Suddenly we had a new, actually, we HAD a strategy, an official strategy that we wanted to publish internationally... We have a very, very focused management, who rather want us to publish one high ranked article every year than just have a lot of small publications in minor journals. (2)

Additionally, researchers spoke about the personal interactions between themselves and management, and how that had changed over time, becoming more active in pressuring researchers to achieve specific aims: "Management interferes a lot more in my research work and want to shape my behaviour, also publication behaviour, than was the case 20 years ago (8)". In the humanities department, there is a less formalistic approach and no strict hierarchy of publications, but still management pressure is clear: "when I was interviewed for my position as associated 
professor, the only thing that the head of the department said was that you have to publish more in English (1)".

Here we can see the close interaction between management pressures and the internal pressures of research for their career. In these terms, the picture presented is stark: "if you want to make a good career at this department you should target these journals [i.e. those on the abovementioned Financial Times list] (8)". It is presented as something that leaves little room for decisions or manoeuvre on the career path:

when you are in a process where you have not met your final destination so to speak, then it is quite important that you focus on the indicators that matters in order to affect whether or not or how fast you can be promoted. So, from that point of view I don't think English or Danish is really a choice. It's given. (3)

\section{English}

There are also push factors away from English, though these tend to situate themselves more at the level of publication, in terms of the choice of subject, methodology and the processes of thinking and writing, which in some ways are more restrictive in English. Subjects of study are not equally interesting to all audiences, and it can be a challenge to take something that is of interest locally or nationally and make it engaging for an international audience. "So perhaps discussions in a publication that would be relevant in a Danish context might be less relevant in an international and global context (8)". There is thus a push away from local knowledge, or stated even more dramatically: "it destroys a lot of the local knowledge (5)". Unless a subject can be made of interest to an international audience, it will not be publishable in English. A researcher who also has journal editorship experience, comments on why that might be the case, and we see that it ties at least in part to what is interesting:

I have also been doing a lot of case studies. There can be a case that is not only unique but is also based on a very particular regulation that only exist in Denmark. You should probably also ask yourself as a researcher then, is that really interesting? (3) 
One of the ways to make a subject interesting internationally is to focus more on theory:

So, you do write in different ways when you address a broader public of literary scholars, you tend to theorize more, you don't do readings as much, you don't [do] history as much. There needs to be some kind of theoretical edge to it in order to go through within this larger audience. (6)

More specifically, and in line with what Lillis and Curry (2010) have argued, the key factor is not just about being interesting to an abstract international audience, rather the definition of what is interesting is shaped by journals and their country of publication. "When we say internationalization at Aarhus University, it is very much in an American, a US context (1)". So having a theoretical focus in the publication is not necessarily enough, it also needs to be a particularly type of theory: "When you have a theoretical interest that is not well represented in the English-speaking world, you end up a little bit alone (4)". In the School of Management, this meant that trends in the US and to a lesser extent the UK steered the type of research being done. In the following example, the researcher talks about the difficulty of getting conceptually based research published in her field:

And some of the strongest within this field have been France and Germany, and Denmark also, in many ways we have had this tradition, but it is very difficult actually to publish anything on that because it is a more rationalistic approach, whereas when you go into the US, then they will just have you look at some much more empirical things... I also think that the US research methods are blind to some social values. (5)

In the humanities, we still find a significant share of publications in Danish, which provides a chance to more fully explore the reasons and trade-offs behind this practice. One issue that came up several times was the choice of examples that get used in an English as opposed to a Danish publication. Several authors describe the challenge of making a theoretical argument relevant by adjusting the examples they use to ones that resonate with an international audience: "I mean... which writers can I 
write about in the larger international circuit? Only very few, only those who are already well famous (6)". While it is not seen as impossible to undertake the task of introducing lesser known examples, for instance newer writers in literature, it increases the challenge of getting work published. If the main thrust of the article is theoretical then, as one researcher describes it: "you might want to change your examples for Scandinavian/ Danish to examples who are for the U.S., so I have done that... sometimes... then you also change your research subject in some ways (1)". On the other hand, in other sub-fields this is something of a non-issue: "it doesn't necessarily matter what cases I study, it is the theoretical development and then it doesn't matter if it is a Danish or an English case. And a lot of the Danish cases that I study usually have quite a lot of international attention anyway (7)".

So, in terms of both the subject and the methodological approach, there is evidence that English does not only expand possibilities through its large audience but also, in some ways, constrict them. In other words, researchers focusing on local knowledge may be pushed away from English.

A third way in which researchers are pushed away from English has to do directly with language. In this, there are three aspects: concept translation, nuance and thinking. Concepts are determined by the choice of language. While in many (maybe most) cases there are adequate translations, there are times that a particular language expresses an idea more effectively: "there are things you can say and think in Danish and German that are foreign entities in the English language. Concepts and lines of thought that are essential in much of my work has been extremely difficult to transpose into English because there was no translation for them (4)". This in part has to do with the way in which language is constructed: "in Danish you can put words together. Like in German, so... so you build up, sort of conceptually, you can build up systems... for instance I can make a word, within my field in Danish, that probably one word would be more or less a whole line. (Laughter). But I cannot do that [in English] (5)".

All of the interviews were conducted in English, and it was abundantly clear that all the interviewees were fluent and perfectly comfortable in English; however, from their own perspective, writing in English did present challenges that could be seen as push factors. The following pas- 
sage in which the researcher describes an article he recently wrote in Danish, somewhat ironically with an American colleague based for many years in Denmark, sums up many of the overall themes we heard from others, that is, reflecting both an increased level of confidence and nuance and a sense of enjoyment:

about this Danish publication that I did with the American colleague of mine, it was a pleasure to write in your own language. I felt much more competent. I feel more competent when I write in Danish. We are sort of amateurs when it comes to writing in English. We can do it and I think most of us don't have any problem of formulating or getting a message through but of course we don't have the same feel for English as we do for our native [language]. (8)

What the author means in this case by "feel" was developed further by the other researchers. For many of them it had to do with nuance: "the problem can be to write sentences that are much nuanced. It is not at the level of the terminology but it is perhaps the way you construct your sentences (8)". And nuance can also affect other aspects of writing, like humour or engagingness: "I think my language is better in Danish... I am funnier, I make my arguments more clear... my excellent sense of humour when I speak in Danish, and it is kind of lost when you are speaking English because you don't know all the nuances (2)". Another researcher explains that the text he produces in English "might tend to become more boring to read also... So perhaps native English-speaking researchers have an advantage, they are probably able to make their publications more reader-friendly, more interesting to read (8)".

The issue of language mastery also came up in several interviews, both from the perspective of writing and understanding: "I master the Danish language in a completely different way than I master English... and I actually wonder how many people really master the English language... I am actually quite worried about that, that we don't get the same sense of what language means (5)". Reflecting on the desire of students for texts and teaching materials in Danish, another researcher shifts the question from understanding to time pressure: "I don't know if they understand it better, but it is easier for them to read, and I think it is faster for them to read (2)". Time pressures also play a role in writing in English: "I put a 
lot of effort into the English articles I think... and it takes much more time to kind of finish those articles than the ones in Danish (1)".

Finally, there is a direct connection between writing and thinking. Interestingly this also affects the local work environment where the language used can change according to the purpose of the discussion: "We speak Danish, but then sometimes we, if we are discussing papers, we switch to English, because it is easier if the article is written in English anyway (7)". This implies that the process of discussion, thinking and writing are deeply intertwined, as we see in this comment: "language is the medium in which I think, so in order to do my thinking as good as possible, I have to write in Danish. I'm simply better in Danish than in English (6)".

\section{Pull Factors}

\section{Danish}

The push factors described above do not prohibit publication in Danish but make it something that falls outside of normal job expectations, at least in the social sciences. As one researcher explained, you do not publish in Danish "unless you really have your heart in it ... REALLY want to". What does pull researchers into publishing in Danish falls into several categories: identity, students, intellectual public sphere and accessibility to the public.

Particularly in the humanities, scholars reflect on their academic identity as a factor in publishing in Danish: "I am still kind of also seeing myself as a Scandinavian scholar so it is important to ... to do research in Scandinavian language and publish in Scandinavian peer-reviewed journals and things like that (1)". Connecting to and serving students is another: "A lot of our students, they really like to read the Danish chapters and somehow it makes more sense to them (2)". This suggests that comprehension in Danish is higher, which was a belief also shared by others, but another aspect might be just that the speed and ease of reading is better. The flip side is that with teaching now increasingly (and in the Department of Management entirely) being done in English, this factor also has a pull effect in the opposite direction. 
Some variation on the idea of maintaining a public intellectual space in Danish was shared among many of the respondents. Some considered it as valuable in itself: "I think there is a point in keeping Danish as a scholarly language (4)", and this also means supporting Danish journals: "I actually think that there are some pretty good journals in Danish, and I also think that it is, somehow I feel that it is important to keep those journals alive (7)". Others described this as wanting to "engage in the Danish debate (5)", which does not have to be solely academic, but can also cross over into other spheres of society: "where we have scientists discussing literature in English and journalists talking about literature in Danish, we need to have a common space, and that common space must necessarily be in the Danish language (6)". There was an argument made that publishing in Danish was necessary in order to maintain the language itself:

If we want to insist that we have to speak Danish in the state of Denmark, then somehow we also need to have, we need to continue to develop a language that is nuanced enough to do that. And I think that if we don't continue to publish research articles in Danish, then I think at some point the Danish language will be lacking. (7)

In addition, there is from some researchers' side a desire to be accessible to the Danish public. However, on this there was more division. Not all researchers saw research publications as the proper avenue for this sort of dissemination. Some researchers argued for publication in newspapers, public talks and media appearances as a more appropriate means than research publications; more of a "translation of our research, not only into Danish publications, but also into, you know, make it more appealing, more approachable for a Danish speaking audience (2)". While the need to disseminate is still given lip-service, the pressures to do so are less intense than for publishing in English. Speaking about the change over the past decade this researcher explained: "What I am saying is, previously it was felt more important to also communicate and disseminate the results to practitioners - and they do not read English. So therefore of course I had to publish in Danish also (3)". Now, this person publishes primarily in English. 


\section{English}

Researchers identified a broad range of pull factors for publishing in English. Legitimacy, socialization and career advancement correspond in many ways with the push factors. Publishing in English is seen to add legitimacy. In one of the studied environments, there was a division between different sub-fields, which resulted in strong internal competition "because we wanted to legitimize our own research area. I think we used the international journals and conferences and networks as, you know, as a means to try to legitimize and show how important this research area really is (2)". Legitimation from publishing in English also was seen to lead towards other benefits, such as being invited to join in grant applications and international projects. Rather than being a concrete pull, one researcher described a "socialization into an international environment" reflecting that: "it is just something that you feel you should do, and you also, you know this again, this doubleness that I feel that it is more rewarding to write in English, mostly, but it also feels like an obligation to maintain this ecosystem (7)". Sometimes it was stated in more direct terms: "it was natural for me to switch to English (2)" or "we were just very eager to, like, become international (1)".

Perhaps the strongest felt pull factors had to do with the audience for one's work and the international interactions, which were facilitated by publishing in English. Researchers described how they were pulled into English publications because they had begun to undertake cooperative research with other international scholars:

I wrote some articles in the late 90's in Danish, which I translated into English, and they were very well received, and that meant that I began to work together with some international scholars, and in particular some English scholars. And I cooperated with them a lot, and that meant that yeah, I went into publishing in English. (5)

More broadly, though, researchers talk in terms of the field and the vastly expanded audience that English language readership provides:

I think sometimes when I publish in Danish, I think 'bmm, this was actually quite interesting, too bad I didn't publish it in English' (laughter). Sometimes 
that feeling, that it can be maybe a little bit of a waste to write something that is interesting in Danish. (7)

And this is not just about dissemination but also about the quality and amount of feedback that comes: "I am also excited about getting all of these inputs, which is like, I mean if you go into English you have a potentially huge audience and the feedback is much [better] (1)". This in turn leads to an overall improvement in the quality of the publications themselves. Researchers see a direct link between the feedback received through both peer review processes at international journals and less formal interactions with international colleagues and the ultimate quality of an article. So from the level of the conference ("the quality of the conversations that we have on the conferences are better" (2)) to the feedback and perceived higher standards ("we get more high quality reviews and quality feedback when we hand in to high ranked journals, international journals" (2)) to the researcher's self-perception ("it makes you better as a research scholar" (1)), the shift to publishing in English is broadly seen to increase quality.

English publications affect a researcher's prestige and legitimacy and integrate them into the larger international community of their scientific field, "I think for me, it has been important the way that I can get into the international community and get some recognition there (5)" and this is also because one wants to be recognized: "you want to be a part of the field, yeah, you don't want to be overlooked (7)". The choice of publishing in English makes sense because, "of course it gives prestige to publish in the best journal (3)". The national bibliometric system that ranks journals in two levels reinforces this (almost none of the top-level journals are in Danish). One researcher described the efforts they made in their field to push back against the idea that "you can't publish anything that has prestige attached to that, unless you do it in English (7)" by getting some Danish journals included in the level 2 categorization.

In sum, we see that push and pull factors in the migration to English language publication have both positive and negative effects, in terms of what is gained and lost in the migration to English publications (Table 4.2). In the following section, we discuss how a responsible university should both support what is gained and take steps to mitigate against these losses. 
Table 4.2 What is gained and what is lost in the migration to English language

\begin{tabular}{ll}
\hline Gained & Lost \\
\hline Quality & Local knowledge \\
Field relevance/importance & Concepts \\
Intellectual stimulation & Approaches \\
Belonging/scientific community & Nuance \\
Prestige & Humour \\
Legitimacy & Thinking \\
Citations & Time \\
Audience & Dissemination avenues \\
\hline
\end{tabular}

\section{Conclusion: The Need for a More Responsible Language Policy}

As we have shown in this chapter, Danish universities have undergone a massive change in recent decades when it comes to the language in which research publications are published. Today, $86 \%$ of all research publications from Danish universities are published in English. Almost all research publications from the Natural, Technical and Medical Sciences are written in English and aimed at the global scientific community. The Social Sciences seem to be moving in the same direction and in the Humanities, more than half of the research publications are today in English.

This development has, according to the interviewees in our study, clear advantages when it comes to enhancing the quality of research and enabling Danish researchers to take part in transnational scientific networks and communities. On an aggregate level, the shift towards publishing in English language journals has further helped to draw attention to research produced in Denmark, making it possible for Danish universities to assert themselves in international competition.

However, as the researchers interviewed in our study made clear, something is also lost in this transition towards English language publications. Some researchers state that they think and write better in Danish. They are, for example, able to express themselves with more nuance and humour. They also from time to time find it hard to translate key concepts into English. English language journals_especially high impact 
journals - furthermore seem to be less interested in cases from small countries, in preference for Anglo-Saxon cases, and favour particular theoretical and methodological approaches over others. Finally, the migration to English also seems to have had a negative impact on the Danish language public sphere-according to the interviewees it even may have been a factor in the closing down of Danish language journals like Grus and Kritik.

An important question related to the context of this book then is, how a responsible university should respond to the development towards more English language publications. It is not an easy question to answer. Universities are on the one hand expected to perform and compete globally, while they on the other hand still have obligations nationally and locally. This is not least the case for Nordic universities, which primarily are public entities financed by tax payments. According to the Danish University Act, Danish universities have an obligation to "... conduct research and offer research-based education at the highest international level within its academic fields". The transition to publishing more in English undoubtedly makes it easier for universities to live up to these two obligations. However, universities also have a third obligation:

The university must collaborate with the external environment and contribute to the development of international collaboration. The university's research and educational results must contribute to promoting growth, prosperity and the development of society. As a central knowledge-based body and cultural repository, the university must exchange knowledge and competences with society and encourage its employees to take part in the public debate. (Uddannelses- og forskningsministeriet 2011)

In relation to this third mission, the transition to English language research publications might be more problematic, because this activity mostly takes place in the local language which also provides a greater local absorptive capacity in terms of the local population's ability to make use of disseminated knowledge. Especially worrying is, as mentioned above, the closing down of high-quality Danish language journals, which dealt with local as well as international cases, and helped translate international debates and issues into a Danish context, contributing in turn to keeping a Danish language public sphere vibrant. 
This chapter shows that there is a need for starting a discussion on what universities, not just in Denmark but everywhere in non-Anglophone countries, can do to battle the negative consequences of the transition to English while at the same time holding on to the benefits of this movement. One place to begin could be to ask if English is, in all cases, better or if more room needs to be given to the national language. Bibliometric systems, reward systems and grant systems together with carrier systems all seem to value English language publications more than national language publications. However, it might be time to start developing more nuanced understandings of English versus national language publications. It should be recognized that the current buzzwords of excellence, impact and relevance are context dependent, and that they can be achieved in local languages albeit with slightly different, though not necessarily less important, results. The responsible university should therefore develop ways to evaluate and recognize quality, impact and relevance in all three of its main missions with consideration given to whether and how language choice reflects and furthers the objectives of the research outputs.

Acknowledgements The authors would like to thank Jens Peter Andersen, senior researcher at the Danish Centre for Studies in Research and Research Policy (CFA), who helped us by making the language algorithm, setting up data and answering questions regarding PURE data. We would also like to thank Henrik Skadhauge Clausen and Nicolaj Veje Pedersen, librarians at Aarhus University Library, who kindly extracted PURE data for us, made comparisons between data in PURE and data from the national database and helped us understand the data. Furthermore, Lotte Faurbæk from the Danish Agency for Science and Higher Education, The Ministry of Higher Education and Science, has been helpful in sending us national bibliometric data. Anna-Kathrine Bendtsen, Astrid Marie Kierkegaard-Schmidt, Anders Møller Jørgensen, Emal Sadeq Aqazadeh, Signe Nygaard and Olivia Hesselholt Dupont Igens, student assistants at CFA, have helped us with various practical tasks such as transcribing interviews, extracting data, validating publication language, and so on. We would also like to thank Anna Kristina Hultgren, Senior Lecturer at the Open University, for her kind and thorough review of our chapter and for her many helpful suggestions for improvements. Finally, our interviewees should also be thanked for helping us making sense of the shift in publication patterns. 


\section{Notes}

1. John Benjamins Publishing Company ISSN 2590-0994.

2. See Aarhus University's homepage for more information on students, staff and rankings: https://international.au.dk/about/profile/keystatistics/.

3. The interviews were conducted in August and September 2018. We interviewed eight researchers from the two scientific environments. The interviews were transcribed and coded in MAXQDA, using a coding strategy combining both structural and in vivo codes.

4. When we here and in the following refer to research publications, we mean journal articles and review articles, books and book chapters, $\mathrm{PhD}$ and doctoral theses, reports and report chapters, and conference papers that have been published and categorized as "scientific" rather than "popular" or "educational".

5. By "main scientific areas" or just "main areas" we here and in the following refer to a division of all the scientific fields represented at Danish universities into four groups: Humanities, Social Sciences, Medical Science, and Natural Science and Technology.

6. At the national level, we only analyse data from 2010 onwards due to data accessibility and data quality. Data at the national level is from "Forskningsdatabasen.dk", which is a publicly available database. At Aarhus University we have received and analysed data reaching back to 2001. The data is from the local PURE (Research Information Management System) database. Within this system, researchers register their publication, including the language of the publication, and librarians validate the registration. The data is not perfect. However, we have checked the validity of the categorization of language with help from an algorithm and by manual coding. Less than $1 \%$ of the publications were incorrectly registered, and the errors seem to be random (English language publications registered as Danish or Danish publications registered as English).

7. The Department of Management was established in 2011 as part of several mergers at Aarhus University. When analysing publications at the department level, publications from merged departments are included. For instance publication from the former Department of Marketing and Department of Management are also included. For the history of the mergers, see: http:// bss.au.dk/om-aarhus-bss/profil-og-strategi/aarhus-bss-historie/.

8. The School of Communication and Culture is also a result of mergers. As it is the case with the Department of Management, publications from merged departments are included in the analysis. 


\section{References}

Altbach, P. G. (2013). The Imperial Tongue. In The International Imperative in Higher Education. Global Perspectives on Higher Education. Rotterdam: Sense Publishers.

Ammon, U. (2001). The Dominance of English as a Language of Science: Effects on Other Languages and Language Communities. New York: Mouton de Gruyter. Bull, T. (2004). Dagens og gårdagens akademiske Lingua Franca [Today's and Yesterday's Academic Lingua Franca]. In D. F. Simonsen (Ed.), Språk i kunnskapssamfunnet. Engelsk-eliternes nye latin? [Language in the Knowledge Society. English - The New Latin of the Elites?]. Oslo: Gyldendal Akademisk.

Flowerdew, J. (1999). Problems in Writing for Scholarly Publication in English: The Case of Hong Kong. Journal of Second Language Writing, 8(3), 243-264. Gazzola, M. (2012). The Linguistic Implications of Academic Performance Indicators: General Trends and Case Study. International Journal of the Sociology of Language, 216, 131-156.

Gregersen, F. (Ed.). (2014). Hvor parallelt. Om parallellspråkighet på Nordens universitet [How parallel. On parallellingualism at the Nordic university] with contributions by Frans Gregersen, Olle Josephson, Sebastian Godenhjelm, Monica Londen, Jan-Ola Östman, Ari Páll Kristinsson, Haraldur Bernharðsson, Unn Røyneland, Gjert Kristoffersen, Marita Kristiansen, Jacob Thøgersen, Taina Saarinen, Anna Kristina Hultgren og Linus Salö. Nordisk Ministerråd 2014. Denmark: TemaNord 2014:535.

Hanauer, D. I., \& Englander, K. (2011). Quantifying the Burden of Writing Research Articles in a Second Language: Data from Mexican Scientists. Written Communication, 28(4), 403-416.

Hultgren, A. K. (2014a). Whose Parallellingualism? Overt and Covert Ideologies in Danish University Language Policies. Multilingua, 33(1-2), 61-87.

Hultgren, A. K. (2014b). English Language Use at the Internationalised Universities of Northern Europe: Is There a Correlation Between Englishisation and World Rank? Multilingua, 33(3-4), 389-411.

Kaplan, R. B. (1993). The Hegemony of English in Science and Technology. Journal of Multilingual and Multicultural Development, 14, 151-172.

Kuteeva, M., \& McGrath, L. (2014). Taming Tyrannosaurus Rex: English Use in the Research and Publication Practices of Humanities Scholars in Sweden. Multilingua, 33(3-4), 365-387.

Lillis, T., \& Curry, M. J. (2010). Academic Writing in a Global Context. The Politics and Practices of Publishing in English. London and New York: Routledge. 
Madsen, M. (2008). "Der vil altid vare brug for dansk". En undersøgelse af 11 naturvidenskabelige forskeres grunde til at valge henholdsvis dansk og engelsk $i$ deres arbejde ["There will always be a need for Danish". An examination of 11 Natural scientists' reasons for choosing English and Danish respectively in their work]. Københavnerstudier i Tosprogethed, bind 48. Copenhagen: Copenhagen University.

Martín, P., Rey-Rocha, J., Burgess, S., \& Moreno, A. I. (2014). Publishing Research in English-Language Journals: Attitudes, Strategies and Difficulties of Multilingual Scholars of Medicine. Journal of English for Academic Purposes, $16,57-67$.

Montgomery, S. L. (2013). Does Science Need a Global Language?: English and the Future of Research. Chicago: University of Chicago Press.

Mortensen, J., \& Haberland, H. (2012). English_-The New Latin of Academia? Danish Universities as a Case. International Journal of the Sociology of Language, 216, 175-197.

Petersen, W. (1958). A General Typology of Migration. American Sociological Review, 23(3), 256-266.

Portes, A., \& Böröcz, J. (1989). Contemporary Immigration: Theoretical Perspectives on Its Determinants and Modes of Incorporation. International Migration Review, 23(3), 606-630.

Saarinen, T., \& Taalas, P. (2017). Nordic Language Policies for Higher Education and Their Multi-layered Motivations. Higher Education, 73(4), 597-612.

Sørensen, M. P., \& Schneider, J. W. (2017). Studies of National Research Performance: A Case of 'Methodological Nationalism' and 'Zombie Science'? Science and Public Policy, 44(1), 132-145.

Sørensen, M. P., Bloch, C., \& Young, M. (2016). Excellence in the KnowledgeBased Economy: From Scientific to Research Excellence. European Journal of Higher Education, 6(3), 217-236.

Swales, J. M. (1997). English as Tyrannosaurus Rex. World Englishes, 16(3), 373-382.

Uddannelses- og forskningsministeriet. (2011). The Danish University Act. Retrieved February 14, 2019, from https:/ufm.dk/en/legislation/prevailinglaws-and-regulations/education/files/the-danish-university-act.pdf.

Wächter, B., \& Maiworm, F. (2014). English-Taught Programmes in European Higher Education. The State of Play in 2014. Bonn: Lemmens Medien GmbH. Wagner, C. S. (2008). The New Invisible College: Science for Development. Washington, DC: Brookings Institution Press. 
Open Access This chapter is licensed under the terms of the Creative Commons Attribution 4.0 International License (http://creativecommons.org/licenses/ by/4.0/), which permits use, sharing, adaptation, distribution and reproduction in any medium or format, as long as you give appropriate credit to the original author(s) and the source, provide a link to the Creative Commons licence and indicate if changes were made.

The images or other third party material in this chapter are included in the chapter's Creative Commons licence, unless indicated otherwise in a credit line to the material. If material is not included in the chapter's Creative Commons licence and your intended use is not permitted by statutory regulation or exceeds the permitted use, you will need to obtain permission directly from the copyright holder. 